\title{
STATISTICAL ANALYSIS ON FUNCTIONAL AND RADIOGRAPHIC RESULTS AFTER USE OF LOCKED VOLAR PLATE FOR FRACTURES OF THE DISTAL RADIUS
}

Daniel Gonçalves Machado', Sergio Auto da Cruz Cerqueira', Rodrigo Ribeiro Pinho Rodarte ${ }^{2}$, Carlos Alberto de Souza Araújo Netto ${ }^{3}$, Marcelo Bezerra de Mathias ${ }^{4}$

\section{ABSTRACT}

Objectives: To evaluate the functional results from using a fixed-angle locked volar plate for treating fractures of the distal extremity of the radius, using the DASH (disorders of the arm, shoulder and hand) questionnaire and its radiographic correlation with the Lidström classification. Methods: Thirty patients with unstable fractures of the distal extremity of the radius were evaluated after they had undergone a surgical procedure consisting of open reduction and internal fixation using a fixed-angle locked volar plate, at the Military Police Central Hospital of Rio de Janeiro between 2008 and 2009. The results were assessed based on range of motion, DASH protocol scores and radiographies with the Lidström classification. Results: The mean age of the patients in the study was 51 years. The mean DASH score was 11.9 points. It was observed that the radiographic findings did not influence the DASH score. It was found that flexion, pronation, supination and radial deviation correlated with the DASH score. Conclusions: The study showed that subjective functional outcomes using the DASH protocol, obtained from using a locked volar plate to treat fractures of the distal extremity of the radius, are influenced by the range of motion, and especially by the flexion, supination, pronation and radial deviation of the wrist after surgery. There is no correlation between the radiological parameters of either the normal or the operated radius, and the subjective functional outcomes assessed using the DASH protocol.

Keywords - Statistical Analysis; Radius Fractures; Bone Plates; Fracture Fixation; Retrospective Studies

\section{INTRODUCTION}

Fractures of the distal extremity of the radius are complex lesions, of variable prognosis that depends on the type of treatment used and whether any associated lesions are present. They occur most frequently in adult patients after the fourth decade of life and comprise around 10 to $20 \%$ of all fractures attended as emergencies. This group also has the highest rates of complications and hand dysfunctions, which affect the capacity to work ${ }^{(1)}$. These are among the most frequently seen fractures of the upper limbs and, although different techniques for treatment exist, there is still no consistent scientific evidence that would allow secure decision-making regarding the appropriate treatment, particularly in cases of unstable fractures ${ }^{(2,3)}$.

In the literature, a wide variety of treatment methods for fractures of the distal extremity of the radius can be found, and this variety can be explained by the complexity of these fractures. However, there is no consensus regarding the results obtained ${ }^{(4)}$.

Recently, some studies have shown that fractures with signs of instability do not have good results when treated using conservative methods, and that skewed consolidation occurs in up to $70 \%$ of them ${ }^{(5)}$. Therefore, anatomical reduction with restoration of joint congruence, by means of surgical stabilization, is currently the treatment recommended for unstable fractures of the distal extremity of the radius.

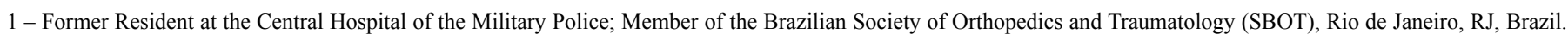

2 - MSc in Public Health; Preceptor of Medical Residence, Central Hospital of the Military Police, Rio de Janeiro, RJ, Brazil.

3 - Orthopedist responsible for the Hand Surgery Group, Central Hospital of the Military Police, Rio de Janeiro, RJ, Brazil.

4 - MSc in Orthopedics; Head of the Orthopedics and Traumatology Service, Central Hospital of the Military Police, Rio de Janeiro, RJ, Brazil.

Work performed at the Orthopedics and Traumatology Service, Central Hospital of the Military Police of the State of Rio de Janeiro (HCPM-RJ).

Correspondence: Rua Hadock Lobo, 379/602 - Tijuca - 20260-131 - Rio de Janeiro, RJ, Brazil. E-mail: daniel.machado@globo.com

Work received for publication: August 1, 2011; accepted for publication: August 26, 2011.
}

The authors declare that there was no conflict of interest in conducting this work 
Several surgical techniques have already been described and these include stabilization with Kirschner wires, external fixation and internal fixation using plates. There are divergent views regarding the best option for treatment, and the treatment implemented is individualized for each case. The factors taken into consideration in this include the characteristics of the fracture, the patient's age and profession, whether the patient does any sports activities, early mobilization, the degree of use of the upper limb and the orthopedic surgeon's experience.

Internal fixation using a dorsal plate, which is greatly advocated, achieves anatomical reduction with good stability. However, a variety of complications have been documented, including irritation of the subcutaneous tissue, tenosynovitis of the extensor muscles, rupture of the extensor tendons and even chronic pain ${ }^{(6)}$. In view of this, fixed-angle locked volar plates for the distal extremity of the radius have gained much space among orthopedic surgeons, since these not only provide stable fixation but also avoid the abovementioned complications ${ }^{(6-9)}$.

Today, the quality of life achieved through the functional and radiographic results from surgical treatment of fractures of the distal extremity of the radius has gained importance. The need for anatomical reduction, preservation of soft tissues and early mobilization has been correlated with the aims of preventing functional incapacity and chronic pain in patients, both immediately after the operation and subsequently. This can be obtained through stable fixation and early mobilization and rehabilitation. Functional incapacity following a fracture can be expressed as the difference between an independent life and the need for permanent home help in performing tasks of daily life.

The aim of the present study was to evaluate these patients' functional results, by means of using the DASH protocol, measurements of wrist range of motion and postoperative control radiographic assessments, and to conduct statistical analysis on the use of fixed-angle locked volar plates for treating fractures of the distal extremity of the radius.

\section{MATERIALS AND METHODS}

A retrospective observational study was conducted at the Central Hospital of the Military Police of the State of Rio de Janeiro, based on the medical files and radiographs of patients admitted to the Orthopedics and
Traumatology Service who underwent surgical procedures to treat unstable fractures of the distal extremity of the radius between 2008 and 2009. There were 11 patients in 2008 and 19 in 2009 . The following types of patient were excluded: patients with an immature skeleton; patients with less than 12 months of postoperative follow-up; patients presenting an exposed fracture of the wrist; patients with an ipsilateral fracture of the shoulder or elbow; and patients who presented ligament lesions of the ipsilateral carpus.

Basic sociodemographic data on the patients were obtained and recorded: age, sex, date of the surgery, side operated and dominant hand, among others. Clinically, wrist range of motion was observed in terms of flexion-extension, pronation-supination and radioulnar displacement, through using a goniometer. Patients without adequate medical documentation were not included in the study.

The fractures were classified preoperatively by means of radiographs on the wrist, in anteroposterior and lateral views, in accordance with the universal classification proposed by Cooney and Berger. All the fractures were intra-articular: there were 27 unstable reducible cases, two non-reducible cases and one complex case. In addition to using the classic instability criteria of Lafontaine et $\mathrm{al}^{(10)}$, new parameters from recent studies were used for indicating the surgical procedure, namely: dorsal displacement greater than 20 degrees, dorsal comminution, shortening of the radius greater than $9 \mathrm{~mm}$, involvement of the radiocarpal and distal radioulnar joints, fractures associated with the ulna, separation between the intra-articular fragments greater than $2 \mathrm{~mm}$ and age greater than 60 years ${ }^{(1)}$.

Through using radiographs in anteroposterior and lateral views on both wrists for the purposes of comparatively verifying the surgical reduction, measurements were made on the radial height, radial tilt and volar tilt of the operated and contralateral wrists, with the aim of obtaining an individualized anatomical reduction parameter for each patient (Figure 1). The radiographic measurements were made by at least two of the authors, and the average between the values obtained was documented. The control radiograph was evaluated in accordance with the Lidström anatomical-radiological classification for fractures of the distal extremity of the radius, as excellent, good, fair or poor ${ }^{(11)}$ (Table 1).

The functional results were analyzed using the pro- 


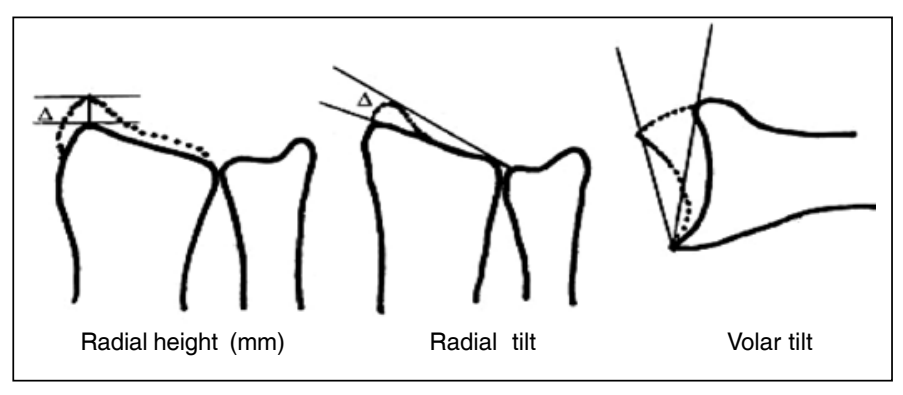

Figure 1 - Measurements on the distal extremity of the radius, using the unaffected side as the parameter.

Table 1 - Anatomical-radiological classification for fractures of the distal extremity of the radius, according to Lidström.

\begin{tabular}{l}
\hline \multicolumn{1}{c}{ Excellent } \\
\hline Insignificant deformity: \\
\hline - Dorsal angle greater than $0^{\circ}$ (neutral) \\
\hline - Radial shortening less than $3 \mathrm{~mm}$ \\
\hline - Loss of radial tilt not more than $4^{\circ}$ \\
\hline \multicolumn{1}{c}{ Good } \\
\hline Small deformity: \\
\hline - Dorsal angle 1-10 \\
\hline - Radial shortening 3-6 mm Fair \\
\hline - Loss of radial tilt 5-9 \\
\hline Moderate deformity: \\
\hline - Dorsal angle 11-14 \\
\hline - Radial shortening 7-11 mm \\
\hline - Loss of radial tilt 10-14 \\
\hline Severe deformity: \\
\hline - Dorsal angle greater than $15^{\circ}$ \\
\hline - Radial shortening greater than $11 \mathrm{~mm}$ \\
\hline - Loss of radial inclination greater than $15^{\circ}$ \\
\hline
\end{tabular}

tocol for dysfunctions of the arm, shoulder and hand (DASH), translated into the Portuguese language. The DASH protocol is formed by 30 questions with five response options for each item. The final score is calculated such that 0 represents absence of functional incapacity and 100 represents complete functional incapacity of the upper limb evaluated ${ }^{(12)}$. The lower the calculated DASH score is, the better the patient's quality of life is and the greater the degree of satisfaction is.

The functional results, including the range of motion and the DASH score, were compared with the anatomical-radiographic parameters. The results were correlated and statistically analyzed using SPSS 13.0. Initially, an exploratory analysis was performed on the central trend and dispersion measurements, for the variables obtained. Subsequently, since some variables were numerical and others were categorical, correlation coefficients were used for the numerical variables and the Mann-Whitney U test was used for both the numerical and the categorical variables.

\section{RESULTS}

\section{Clinical results}

The study group included 30 patients (16 men and 14 women) of mean age 51 years (range: 20 to 84 years). The fractures occurred in the dominant upper limb in 17 cases and in the non-dominant limb in 13 cases. The right arm was affected in 17 cases and the left arm in 13 cases. The commonest injury mechanism was a fall from a standing position (25 patients). Three patients suffered falls from heights greater than two meters and another two were victims of traffic accidents. The mean length of the postoperative follow-up was 17.5 months (range: 12 to 26 months).

Wrist pain was only present in a minority of the patients. After a minimum of 12 months had elapsed from the time of the surgery, 23 patients did not present any pain, five had minimal or slight pain and two had moderate pain, mainly during activities that required a large range of motion and/or an impact on the wrist joint. The clinical and functional results were mostly satisfactory. The mean DASH score was 11.9 points (range: 0 to 54), thus confirming the patients' good functional capacity. The patients had greatest difficulty with regard to their ability to carry heavy objects (more than $5 \mathrm{~kg}$ ), perform activities that required an impact and doing heavy domestic tasks. All the patients were capable of returning to their domestic activities or to their work after this study. The following mean ranges of motion were documented: wrist flexion of $65^{\circ}$ (normal up to $80^{\circ}$ ), extension of $61^{\circ}$ (normal up to $70^{\circ}$ ), pronation of $82^{\circ}$ (normal up to $90^{\circ}$ ), supination of $84^{\circ}$ (normal up to $90^{\circ}$ ), ulnar displacement of $40^{\circ}$ (normal up to $45^{\circ}$ ) and radial displacement of $12^{\circ}$ (normal up to $15^{\circ}$ ).

\section{Radiographic results}

During the study, all the fractures were found to have consolidated. The radiographic results were obtained by measuring the operated radius and comparing this with the unaffected contralateral radius. The following mean measurements were obtained for the operated radius: radial tilt of $20.2^{\circ}$, radial height of $9.7 \mathrm{~mm}$ and volar tilt of $5.6^{\circ}$. Out of the total of 30 patients, 24 were classified as good or excellent, of whom seven were excellent (Figure 2) and 17 were good according to Lidström, which corresponded to $80 \%$ of the patients in the study. Four patients were classified as fair and two as poor. The angles of the distal extremity of the radius on the unaffected side 
were evaluated, and the following mean values were obtained: radial tilt of $22.2^{\circ}$, radial height of $11.1 \mathrm{~mm}$ and volar tilt of $10.1^{\circ}$ (Figure 3 ).

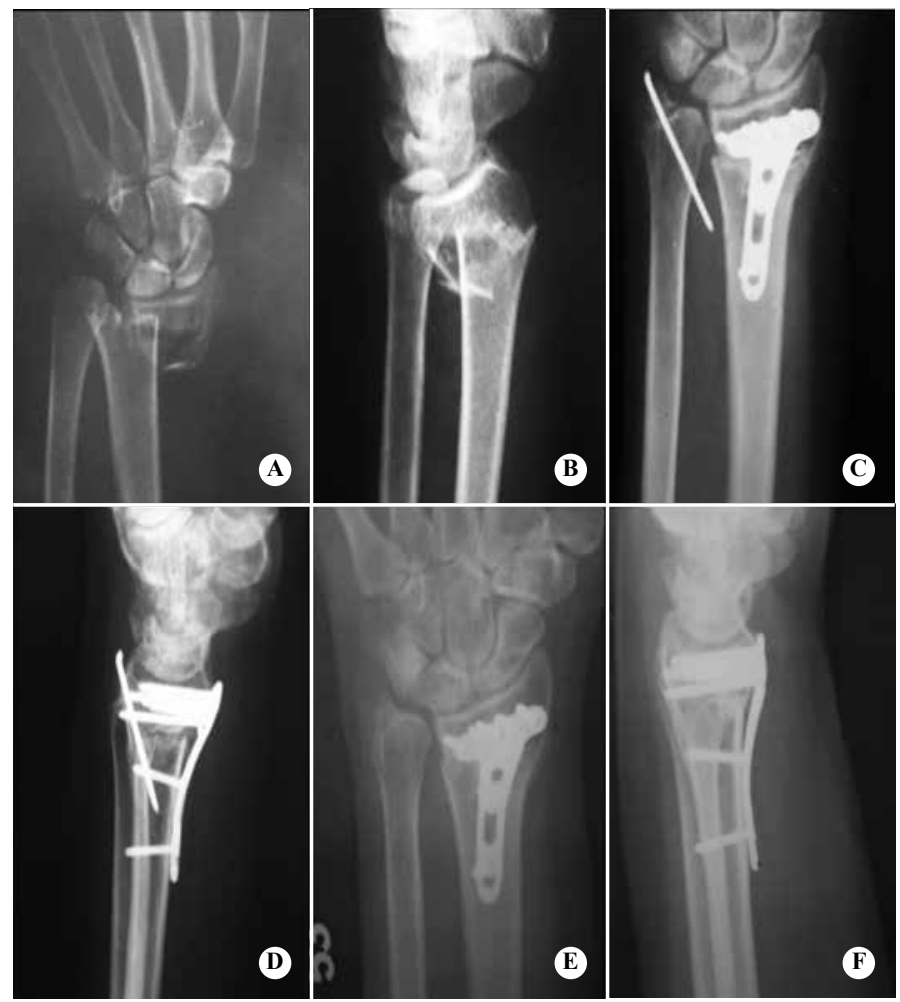

Figure 2 - Preoperative radiographs on the wrist in $(A)$ anteroposterior view and $(B)$ lateral view, showing fracture of the distal extremity of the radius extending to the distal radioulnar joint, with associated fracturing of the styloid process of the ulna. (C and D) osteosynthesis was performed using a $2.4 \mathrm{~mm}$ locked volar plate on the radius, with fixation using a Kirschner wire in the ulna. This was removed 12 weeks after its placement. Twenty-three months after the first surgical procedure, a new radiological control was performed in $(E)$ anteroposterior view and $(F)$ lateral view.

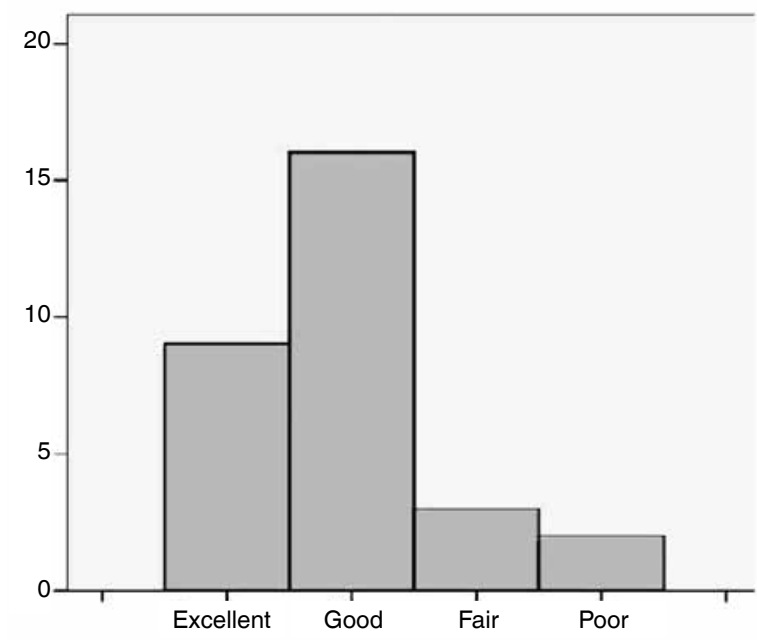

Figure 3 - Histogram showing radiographic evaluation according to Lidström and the number of patients in each stage.

\section{Correlation between clinical and radiographic results}

The functional and radiographic results were correlated by means of statistical analysis. Firstly, an analysis was performed between the DASH score and the documented range of motion of each of the patients in the study. There was no correlation between the DASH score and the extension capacity $(p=0.15)$ or between this score and the ulnar displacement $(p=0.10)$ of the wrist. However, it was observed that the flexion, pronation, supination and radial displacement were correlated with the DASH score, with statistical significance $(p<0.05)$. The higher the DASH score was (i.e. the worse the functional result $)$, the smaller were the flexion $(p=0.01)$, pronation $(\mathrm{p}=0.03)$, supination $(\mathrm{p}<0.0001)$ and radial displacement $(p=0.005)$ of the wrist that underwent the surgical procedure after the fracture of the distal extremity of the radius (Tables 2 and 3). Subsequently, an analysis was performed between the DASH score and the radiographic results obtained. The radiographic results did not influence the DASH score. There was no statistical relationship between the DASH score and the radial height or the volar tilt or the radial tilt of the distal extremity of the operated radius.

We observed that the functional results (and notably the DASH scores) for the males were more homogenous that those of the females (Figure 4). On the other hand, no significant correlations were observed with regard to the dominant hand, type of fracture or age.

Table 2 - Descriptive statistics on clinical and radiographic measurements.

\begin{tabular}{c|c|c|c|c|c}
\hline & Range & Mean & Minimum & Maximum & $\begin{array}{c}\text { Standard } \\
\text { deviation }\end{array}$ \\
\hline Age (years) & 64 & 51.8 & 20 & 84 & 2.77 \\
\hline Flexion (degrees) & 50 & 65.8 & 35 & 85 & 2.82 \\
\hline Extension (degrees) & 50 & 61.5 & 30 & 80 & 2.48 \\
\hline Pronation (degrees) & 45 & 82.5 & 45 & 90 & 2.21 \\
\hline Supination (degrees) & 45 & 84.8 & 45 & 90 & 1.67 \\
\hline $\begin{array}{c}\text { Ulnar displacement } \\
\text { (degrees) }\end{array}$ & 15 & 40.8 & 30 & 45 & 0.99 \\
\hline $\begin{array}{c}\text { Radial displacement } \\
\text { (degrees) }\end{array}$ & 10 & 12.3 & 5 & 15 & 0.52 \\
\hline DASH & 54 & 11.9 & 0 & 54 & 2.2 \\
\hline $\begin{array}{c}\text { Length of time after } \\
\text { the operation (months) }\end{array}$ & 16 & 17.5 & 10 & 26 & 0.98 \\
\hline $\begin{array}{c}\text { Radial height (normal) } \\
\text { Radial height } \\
\text { (operated) }\end{array}$ & 6 & 11.1 & 8 & 14 & 0.29 \\
\hline Radial tilt (normal) & 8 & 22.2 & 19 & 27 & 0.37 \\
\hline Radial tilt (operated) & 13 & 20.2 & 12 & 25 & 0.55 \\
\hline Volar angle (normal) & 18 & 10.1 & 0 & 18 & 0.73 \\
\hline $\begin{array}{c}\text { Volar angle (operated) } \\
\text { Rar }\end{array}$ & 27 & 5.6 & -8 & 19 & 1.15 \\
\hline So Daga
\end{tabular}

Source: Data gathered from the medical files of the Central Hospital of the Military Police relating to the years 2008 and 2009 . 
Table 3 - Correlation of DASH with the objective variables.

\begin{tabular}{c|c|c}
\hline Movement & Correlation & p-value \\
\hline Supination $^{*}$ & -0.66 & $<0.0001$ \\
\hline Radial displacement $^{*}$ & -0.5 & $\mathrm{p}=0.005$ \\
\hline Flexion $^{*}$ & -0.46 & $\mathrm{p}=0.01$ \\
\hline Pronation $^{*}$ & -0.4 & $\mathrm{p}=0.03$ \\
\hline Ulnar displacement $^{*}$ & -0.3 & $\mathrm{p}=0.10$ \\
\hline Extension & -0.26 & $\mathrm{p}=0.15$
\end{tabular}

p-value (statistically significant) ${ }^{*}$

Source: Data gathered from the medical files of the Central Hospital of the Military Police relating to the years 2008 and 2009 .

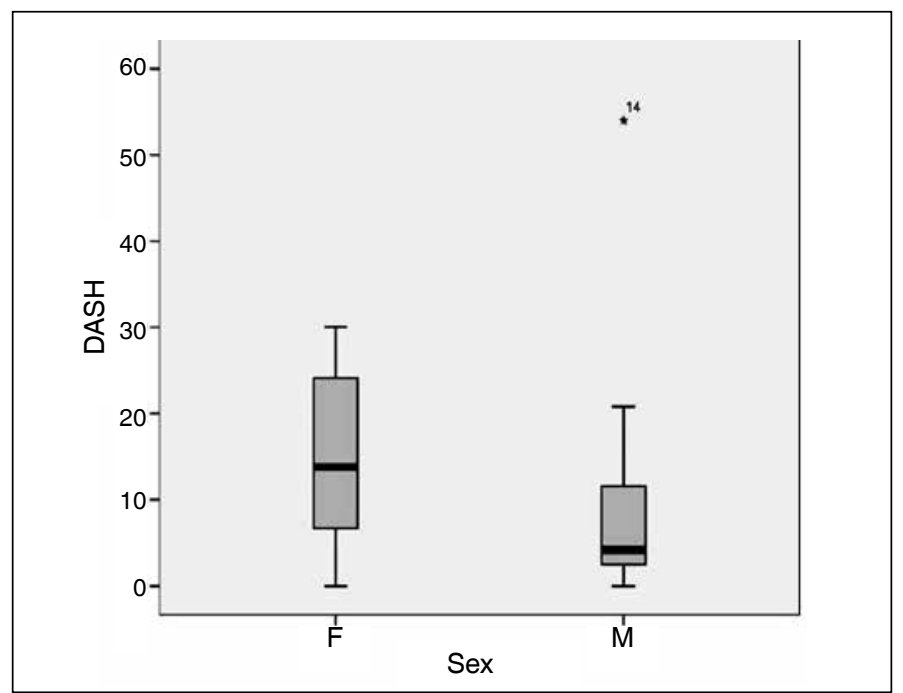

Figure 4 - Boxplot should mean variation in DASH score according to sex.

\section{Complications}

Despite the possible surgical risks inherent to any surgical procedure, open reduction and internal fixation using a locked volar plate did not present any major complication, for any of the patients in the study. There were no cases of tendon irritation in the extensor compartment, or any need to remove the implant. There were no cases of sensitive neuropathy, local deep infection, loss of reduction or nonunion of the fracture. One patient had rheumatoid arthritis and already presented deformity of the fingers and mild limitation of wrist range of motion at the time when the surgery was performed. Nonetheless, this patient's functional and radiographic results were satisfactory. Four patients needed surgical interventions because they presented associated lesions. One patient presented a lesion of the pelvic ring with a surgical indication, and this underwent fixation using an external AO/ASIF fixator. One patient underwent fixation using a plate and sliding screw for the hip because of an associated transtrochanteric fracture of the femur. In another case, the patient presented bilateral fractures of the distal extremity of the radius, and osteosynthesis was performed using a plate on the unstable intra-articular fracture and using Kirschner wires in the extra-articular fracture, in accordance with the inclusion criteria for performing open reduction and internal fixation in this study. Another patient underwent fixation using a one-third cane plate, because of an associated ankle fracture.

\section{DISCUSSION}

Over the last decade, several studies have been directed towards clarifying which surgical treatment method would be best for fracture of the distal extremity of the radius. In this context, Osada et $\mathrm{al}^{(13)}$ recently documented the increasing popularity of open reduction and internal fixation, especially since the introduction of locked volar plates in 2001. They demonstrated that locked volar plates are well tolerated, allow early mobilization and provide good support for deforming muscle forces after the surgical reduction, even in intra-articular fractures ${ }^{(13)}$. The majority of the studies have used subjective tools for measuring quality of life, such as the Gartland and Werley calculation and the DASH calculation $^{(14,15)}$, while others have given greater emphasis to the radiographic parameters obtained after surgical reduction of fractures of the distal extremity of the radius ${ }^{(11)}$.

Leung et $\mathrm{al}^{(16)}$ reported that better functional and radiographic results were obtained through using locked volar plates, independent of the length of postoperative follow-up, in comparison with using external fixators or percutaneous fixation with Kirschner wires. However, other studies have found that better results from using locked volar plates were only confirmed during the first three months after the operation, and that the results became equal to those from other implants after one to two years of postoperative follow-up ${ }^{(3,14,15,17-20)}$. Although no comparisons were made in the present study between locked volar plates and other types of implant, patients were evaluated with lengths of follow-up of one to three years after the operation, and it was observed that the quality of life and functional result assessed using DASH were satisfactory, independent of the length of postoperative follow-up. We observed that the incidence of pain and functional incapacity one year after the surgery was minimal. Only five patients presented minimal or 
slight pain, and two patients $(6 \%)$ presented moderate pain when performing more intensive activities. This finding is corroborated by the findings of MacDermid et $\mathrm{al}^{(21)}$ and Moore et $\mathrm{l}^{(22)}$, who demonstrated that their patients' pain and functional incapacity decreased progressively with increasing length of follow-up, during the first year after the operation, after the definitive treatment for the fracture of the distal extremity of the radius had been established. In this manner, a situation close to absolute absence of pain was reached.

We did not observe any correlation between the radiographic classification and the functional result. This ratifies the findings of Tsukazaki et al ${ }^{(23)}$, i.e. that the severity of the initial displacement, the involvement of the radiocarpal or distal radioulnar joint and the presence of fracturing of the styloid process of the ulna did not affect the functional result from treating the fracture of the distal extremity of the radius with a fixed-angle plate ${ }^{(23)}$.

Fujii et $\mathrm{al}^{(24)}$ observed that there was no relationship between the functional result and reestablishment of the radiographic parameters of the distal extremity of the radius to the way they were before the fracture. Moreover, in the study by Jaremko et $\mathrm{al}^{(25)}$, patients undergoing conservative treatment for fractures of the distal extremity of the radius were evaluated and it was observed that there was no relationship between the functional results and reduction of the fracture to "acceptable" radiographic levels. Our data confirm the findings of Fujii et al ${ }^{(24)}$ and Jaremko et $\mathrm{al}^{(25)}$, i.e. that the radiological values did not influence the range of motion. No significant difference was observed, given that while some patients with small degrees of mobilization of the wrist presented radiographs that were classified as good or excellent, other patients with a wide range of wrist mobilization presented radiographs classified as fair or poor according to van Eerten ${ }^{(11)}$. Thus, the final change in dorsal tilt of the radius seen on lateral-view radiographs, and the change in radial tilt and height seen on anteroposterior-view radiographs that were produced as routine postoperative check-ups on the patients in the study were inconclusive for affirming that there were any relationship with the range of motion of the wrist.

We found that the range of motion of the wrist joint, and particularly the flexion, pronation, supina- tion and radial displacement were influenced by the DASH score result. There was an inversely proportional relationship between the range of motion of the wrist that underwent the surgical procedure and the DASH score, and this was statistically significant $(p<0.05)$. Although wrist extension and ulnar displacement did not show any relationship with the DASH score, and unlike what was documented by Wilcke et $\mathrm{al}^{(26)}$ (who concluded that wrist extension and ulnar displacement were correlated with worse DASH score), we found that with greater flexion, pronation, supination and radial displacement of the wrist, we obtained a better functional result (lower numerical DASH score). Wilcke ${ }^{(26)}$ et al also observed that the correlation between the postoperative radiological findings and the DASH score was weak or insignificant, as discussed earlier.

The present study found that the functional and radiographic result from using locked volar plates for factures of the distal extremity of the radius was very satisfactory, and also did not present any significant postoperative complications. According to Rozental and Blazar ${ }^{(27)}$, their functional results were good or excellent in most cases. However, they found that their rate of complications (such as implant failure with collapse of the fracture) was greater than in previous reports. This led us to reflect on the need for better postoperative rehabilitation and a better surgical technique for this therapeutic approach, in order to avoid such complications. As observed in the study by Chung et $\mathrm{al}^{(28)}$, open reduction and internal fixation enabled early mobilization and an earlier return to normal activities that with plaster-cast immobilization of the wrist for six weeks. However, also like Chung et $\mathrm{al}^{(28)}$ and Berner and Willis ${ }^{(29)}$, the results in terms of final range of motion in the two groups were perceived to be similar, i.e. no significant differences were found. Wakefield et $\mathrm{al}^{(30)}$ also observed that carrying out exercises at home was a form of rehabilitation that was as good as having regular physiotherapy sessions after treatment of non-complicated fractures of the distal extremity of the radius.

\section{CONCLUSION}

We conclude that, based on the functional results according to evaluation using the DASH questionnaire, treatment of unstable fractures of the distal 
extremity of the radius using fixed-angle locked volar plates is a technique with consistent results even with radiographic classification as insufficient (fair or poor). This study demonstrates that the subjective functional results from using the DASH protocol, obtained through using locked volar plates to treat fractures of the distal extremity of the radius, are influenced by the range of motion, particularly the flexion, supination, pronation and radial displacement of the wrist after the surgical procedure, thus characterizing emphasis on early rehabilitation in cases of this pathological condition.

\section{REFERENCES}

1. Caporrino FA, Belotti JC, Ulson HJR, Toledo LFQ, Reis FB, Machado JKS Fraturas da extremidade distal do rádio e da ulna. In: Pardini Júnior AG, Freitas A. Traumatismos da mão. 4a. ed. Rio de Janeiro: MedBook; 2008. p. 411-45.

2. Brogren E, Petranek M, Atroshi I. Incidence and characteristics of distal radius fractures in a southern Swedish region. BMC Musculoskelet Disord. 2007;8:48.

3. Egol K, Walsh M, Tejwani N, McLaurin T, Wynn C, Paksima N. Bridging externa fixation and supplementary Kirschner-wire fixation versus volar locked plating for unstable fractures of the distal radius: a randomised, prospective trial. $\mathrm{J}$ Bone Joint Surg Br. 2008;90(9):1214-21.

4. Belloti JC, Santos JB, Atallah AN, Albertoni WM, Faloppa F. Fractures of the distal radius (Colles' fracture). Sao Paulo Med J. 2007;125(3):132-8.

5. Koenig KM, Davis GC, Grove MR, Tosteson AN, Koval KJ. Is early interna fixation preferred to cast treatment for well-reduced unstable distal radial fractures? J Bone Joint Surg Am. 2009;91(9):2086-93.

6. Sobky K, Baldini T, Thomas K, Bach J, Williams A, Wolf JM. Biomechanical comparison of different volar fracture fixation plates for distal radius fractures. Hand (N Y). 2008;3(2):96-101.

7. Anakwe R, Khan L, Cook R, McEachan J. Locked volar plating for complex distal radius fractures: Patient reported outcomes and satisfaction. J Orthop Surg Res. 2010;5:51.

8. Krukhaug Y, Gjerdet NR, Lundberg OJ, Lilleng PK, Hove LM. Different osteosyntheses for Colles' fracture: a mechanical study in 42 cadaver bones. Acta Orthop. 2009;80(2):239-44.

9. Smith DW, Henry MH. Volar fixed-angle plating of the distal radius. J Am Acad Orthop Surg. 2005;13(1):28-36.

10. Lafontaine M, Hardy D, Delince P. Stability assessment of distal radius fractures. Injury. 1989;20(4):208-10.

11. van Eerten PV, Lindeboom R, Oosterkamp AE, Goslings JC. An X-ray template assessment for distal radial fractures. Arch Orthop Trauma Surg. 2008;128(2):217-21.

12. Orfale AG, Araújo PM, Ferraz MB, Natour J. Translation into Brazilian Portuguese, cultural adaptation and evaluation of the reliability of the Disabilities of the Arm, Shoulder and Hand Questionnaire. Braz J Med Biol Res. 2005;38(2):293-302.

13. Osada D, Kamei S, Masuzaki K, Takai M, Kameda M, Tamai K. Prospective study of distal radius fractures treated with a volar locking plate system. J Hand Surg Am. 2008;33(5):691-700.

14. Gruber G, Zacherl M, Giessauf C, Glehr M, Fuerst F, Liebmann W, et al. Quality of life after volar plate fixation of articular fractures of the distal part of the radius. J Bone Joint Surg Am. 2010;92(5):1170-8.

15. Lozano-Calderón S, Moore M, Liebman M, Jupiter JB. Distal radius osteotomy in the elderly patient using angular stable implants and Norian bone cement. $J$ Hand Surg Am. 2007;32(7):976-83

16. Leung F, Tu YK, Chew WY, Chow SP. Comparison of external and percuta- neous pin fixation with plate fixation for intra-articular distal radial fractures. A randomized study. J Bone Joint Surg Am. 2008;90(1):16-22.

17. Lozano-Calderón SA, Doornberg JN, Ring D. Retrospective comparison of percutaneous fixation and volar internal fixation of distal radius fractures. Hand (N Y). 2008;3(2):102-10.

18. Rohde G, Haugeberg G, Mengshoel AM, Moum T, Wahl AK. No long-term impact of low-energy distal radius fracture on health-related quality of life and global quality of life: a case-control study. BMC Musculoskelet Disord. 2009;10:106.

19. Rozental TD, Blazar PE, Franko OI, Chacko AT, Earp BE, Day CS. Functional outcomes for unstable distal radial fractures treated with open reduction and internal fixation or closed reduction and percutaneous fixation. A prospective randomized trial. J Bone Joint Surg Am. 2009;91(8):1837-46.

20. Xu GG, Chan SP, Puhaindran ME, Chew WY. Prospective randomised study of intra-articular fractures of the distal radius: comparison between external fixation and plate fixation. Ann Acad Med Singapore. 2009;38(7):600-6.

21. MacDermid JC, Roth JH, Richards RS. Pain and disability reported in the year following a distal radius fracture: a cohort study. BMC Musculoskelet Disord. 2003;4:24.

22. Moore CM, Leonardi-Bee J. The prevalence of pain and disability one year post fracture of the distal radius in a UK population: a cross sectional survey. BMC Musculoskelet Disord. 2008;9:129.

23. Tsukazaki T, Takagi K, Iwasaki K. Poor correlation between functional results and radiographic findings in Colles' fracture. J Hand Surg Br. 1993;18(5):588-91.

24. Fujii K, Henmi T, Kanematsu Y, Mishiro T, Sakai T, Terai T. Fractures of the distal end of radius in elderly patients: a comparative study of anatomical and functional results. J Orthop Surg (Hong Kong). 2002;10(1):9-15.

25. Jaremko JL, Lambert RG, Rowe BH, Johnson JA, Majumdar SR. Do radiographic indices of distal radius fracture reduction predict outcomes in older adults receiving conservative treatment? Clin Radiol. 2007;62(1):65-72.

26. Wilcke MK, Abbaszadegan $\mathrm{H}$, Adolphson PY. Patient-perceived outcome after displaced distal radius fractures. A comparison between radiological parameters, objective physical variables, and the DASH score. J Hand Ther. 2007;20(4):290-8.

27. Rozental TD, Blazar PE. Functional outcome and complications after volar plating for dorsally displaced, unstable fractures of the distal radius. J Hand Surg Am. 2006;31(3):359-65.

28. Chung KC, Shauver MJ, Birkmeyer JD. Trends in the United States in the treatment of distal radial fractures in the elderly. $J$ Bone Joint Surg Am. 2009;91(8):1868-73.

29. Berner $\mathrm{SH}$, Willis FB. Dynamic splinting in wrist extension following distal radius fractures. J Orthop Surg Res. 2010;5:53.

30. Wakefield AE, McQueen MM. The role of physiotherapy and clinical predictors of outcome after fracture of the distal radius. J Bone Joint Surg Br. 2000;82(7):972-6. 